\title{
Analysis of strong wind events around Adelie Land, East Antarctica
}

\author{
Jaya Naithani $\left({ }^{1}\right)$, Stefania Argentini $\left({ }^{2}\right)$, Guy Schayes $\left({ }^{1}\right)$ and Giangiuseppe Mastrantonio $\left({ }^{2}\right)$ \\ ${ }^{(1)}$ Université Catholique de Louvain, Institut d'Astronomie et de Géophysique Georges Lemaître, \\ Louvain-la-Neuve, Belgium \\ ( $\left.{ }^{2}\right)$ Istituto di Scienze dell'Atmosfera e del Clima (ISAC), CNR, Roma, Italy
}

\begin{abstract}
Strong wind events at Dumont d'Urville (DdU), an East Antarctic coastal station, and Dome C, an interior station, were studied to determine if the wind along the Adelie Land coast increases with the approach of the depression from the west of the site or after its passage to the east of it. The events for the year 1993 were studied using synoptic observations, mean sea level pressure charts and composite infrared satellite images. It was found that the winds are enhanced with the approach of a depression from the west towards the DdU coast. The wind increases in response to the decreasing pressure at the coastal site and increasing downslope pressure difference (dp). The wind starts decreasing once the system moves to the east of DdU and the pressure at DdU starts building up, as reported in some earlier studies. The response of wind to the approaching depression is not the same for all the events but depends on the downslope pressure difference and the movement of the depression that is often conditioned by the presence of a blocking high to the northeast. The wind comes down if the system starts penetrating inland due to the presence of the high pressure ridge to the northeast and decreasing dp. It is observed that the winds at Dome $\mathrm{C}$ increase to as high as $17 \mathrm{~m} \mathrm{~s}^{-1}$ with the inland penetration of the depression.
\end{abstract}

Key words strong wind events - cyclones -Dumont d'Urville-Antarctica

\section{Introduction}

The strongest near surface winds are observed in the coastal regions of East Antarctica. The reasons behind these extreme winds are the katabatic flow and the uninterrupted stream of eastward moving extratropical cyclones. However, it is still not clear from the literature if the winds over Adelie Land are strong ahead of the depression or after its passage. According to the studies carried out on strong surface winds at various sites along the Adelie Land coast there are

Mailing address: Dr. Jaya Naithani, Université Catholique de Louvain, Institut d'Astronomie et de Géophysique Geoges Lemaître, Chemin du Cyclotron 2, B-1348 Louvain-la-Neuve, Belgium; naithani@astr.ucl.ac.be conflicting conclusions about the enhancement of winds with the decreasing pressure indicating the approach of the depression from the west or with the building up of pressure after the passage of depression to the east. Kidson (1946) noted that the wind at Cape Denison always increased with the approach of a cyclonic depression. However, Ball (1960) reported that the strongest katabatic winds occur at the coast on the western side of the trough, the katabatic winds on the eastern side being lighter than normal. Tauber (1960) also noted that the strong katabatic winds seem to occur when the geostrophic wind in the free atmosphere was directed offshore. Once again, Loewe (1974) summarised that the surface pressure and pressure changes are correlated with wind speeds at port Martin and Mawson. He (Loewe, 1974) reported that at both stations strong winds are slightly more frequent with falling than with rising pressure. Parish et al. (1993) also reported that it can be stated with confidence that the strong katabatic wind events along the Adelie 
Land coast usually occur with lower than normal pressure in the offshore environment and under falling pressures. However, Parish and Bromwich (1998) reported that it is to be expected that the surface winds would be enhanced on the western side of the low pressure trough and diminished on the eastern side. All these studies were either based on observations (Kidson, 1946; Tauber, 1960; Loewe, 1974) or model simulations (Ball, 1960) or both (Parish et al., 1993; Parish and Bromwich, 1998).

It is unlikely for the winds to be stronger when the system is to the east of the station (to the western side of the depression), i.e., when the system has already moved past the station, as the station level pressure is building up during this period. The basic mechanism responsible for the generation and development of downslope winds are the inversions on the Antarctic slopes and the resulting pressure gradient force directed downslope towards the coast. The inversion pressure gradient force causes the cold dense air mass on the higher plateau, denser than the air some horizontal distance away at the same elevation towards the coast, to descend due to its own gravity towards the coast. The speed of this flow, called the katabatic flow, is proportional to the magnitude of the slope and surface friction, while its direction is governed by the fall line and Coriolis force. Now incorporating the influence of transient eddies as they approach the coast and move past the station, the station level pressure decreases with the approach of the depression from the west. This will further increase the existing pressure gradient force between the coast and the point from where wind originates. In case there was no considerable pressure gradient before, it will be establised with the approach of the depression off the coast. The wind should be stronger during this period. As the system moves past the station to the east the pressure starts building up and the pressure

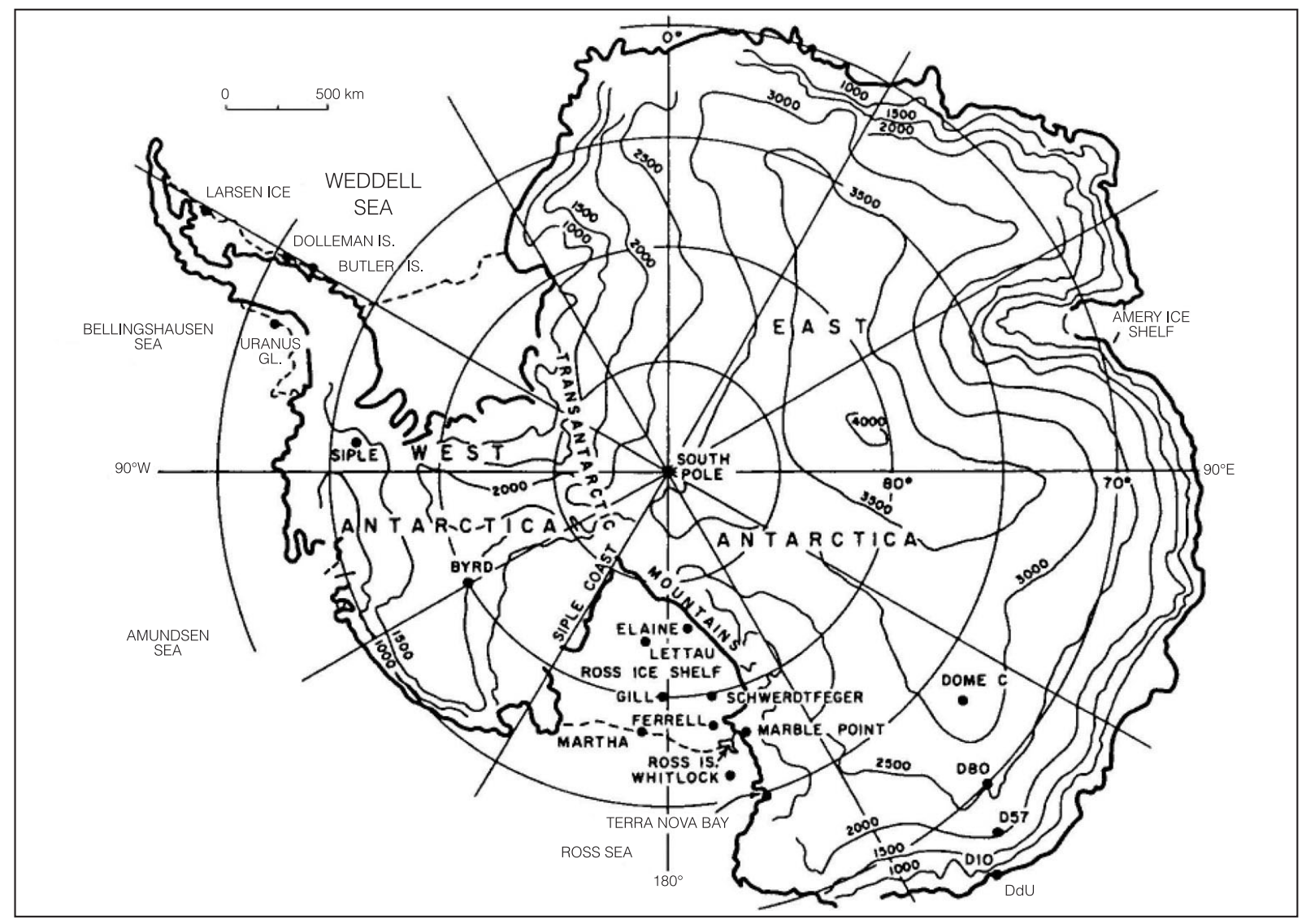

Fig. 1. The map of Antarctica showing height contours and the location of Dumont d'Urville and Dome C. 
gradient becomes less steep, and, the wind should be expected to be low or should cease. The latter, of course, will depend upon several other factors including the availability of cold air mass upslope to be blown past and the downslope pressure gradient. The important factor which should help to prolong the flow is the fact that the presence of the cyclone acts to pull the air mass from the interior, plus it converges this excess mass from near the coast and raises it to higher levels. This upward converged flow will diverge at higher elevation and will flow back to the continents interior and will subsequently subside, and, therefore, helps in the faster replenishment of air mass to feed the gravity flow (Naithani et al., 2001). The removal of the air mass by the low offshore avoids the possibility of increasing pressure at the coast (Egger, 1985) which would otherwise decrease the pressure gradient between the coast and the continent.

Since there have been conflicting conclusions by various researchers on the enhancement of near surface winds with the position of the depression with respect to the coast, we aim to study this once again using simple observations at Dumont d'Urville (DdU, 67.7S; 140E; 40 m a.s.l., fig. 1). Data for Dome C (DC, 75.4S; 123E; $3280 \mathrm{~m}$ a.s.1.) have also been discussed. Winds at DdU originate at/around DC and are southeasterly most of the time. The synoptic situations during the strong wind events at DdU (fig. 1) were studied for some randomly chosen strong wind events from the year 1993. Three hourly ten minute averaged synoptic observations near the surface are complemented by the Mean Sea Level Pressure field (MSLP) of European Centre of Medium-range Weather Forecasts (ECMWF, Shinfield Park, U.K.) and the composite infrared satellite images received from Madison. Three hourly synoptic observations for DdU and DC sites were downloaded from the British Antarctic Survey (BAS, http://www.nerc-bas. ac.uk/public/icd/metlog) and the University of Wisconsin (UW; ftp://amrc.ssec.wisc.edu and http://amrc.ssec.wisc.edu) web sites. The missing data values are replaced by the previous data values. The year 1993 was selected, since the ECMWF data were reanalysed for this year and the late data coming from buoys and ship logs were incorporated. These strong wind events are chosen when the wind speed was more than $20 \mathrm{~ms}^{-1}$ for about one day or more in the four seasons observed at DdU. For convenience, we divided these events on the basis of the movement of depressions according to the MSLP charts and composite infrared satellite images. The depressions along the Antarctic coast are eastward moving and cannot penetrate inland due to the sharp increase in topography, in particular along the East Antarctic coasts (Parish, 1988). However, it was observed that the depressions on occasions penetrate inland. This was the case even in winter months when the circumpolar trough is rather weak and is shifted to its northern limits, further from the coast. In earlier studies conducted for July 1994, the vortices were observed to penetrate inland from around 120E (Pook and Cowled, 1999; Naithani et al., 2002).
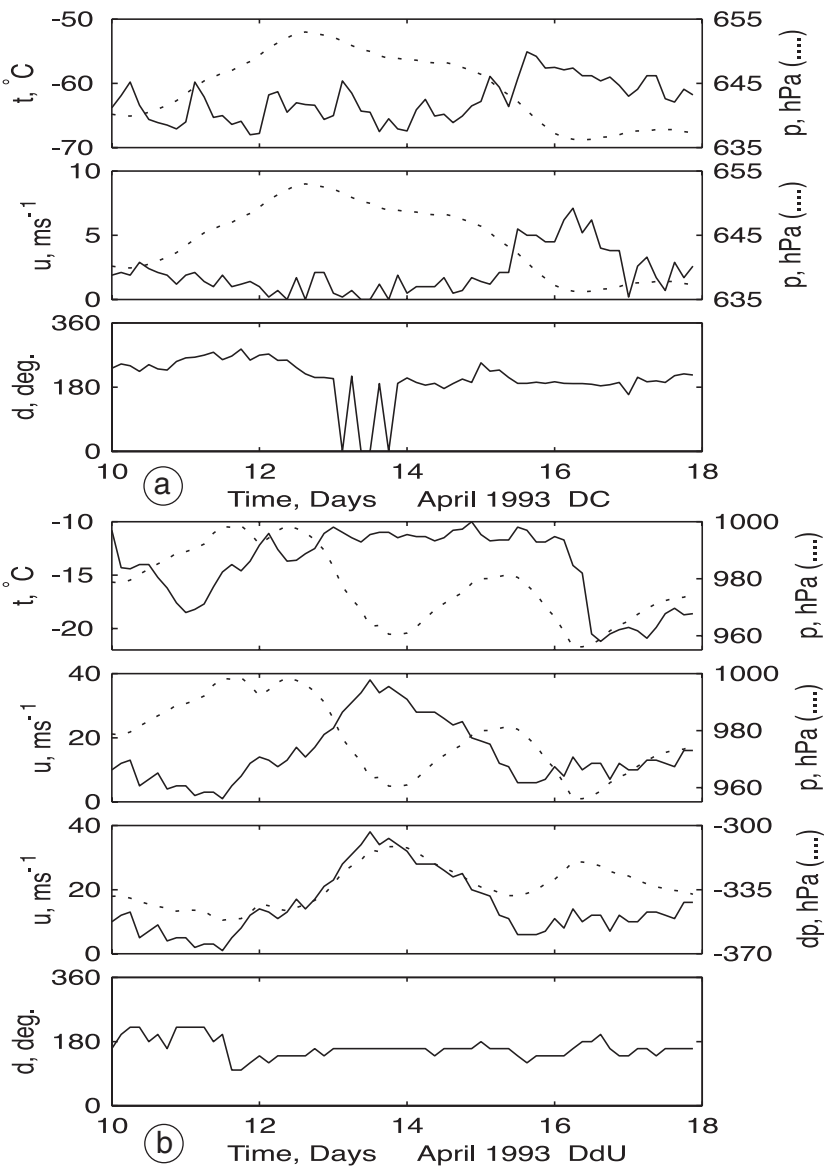

Fig. 2a,b. Time series of meteorological parameters: a) for Dome $\mathrm{C}$; b) for Dumont d'Urville. The figure shows a strong wind event at DdU from 12 to 15 April 1993. 


\section{Observations}

\subsection{Lows passing from west to east of DdU site}

In this category there are situations when the depressions move from the west of the DdU site to the east in their usual flow direction. In other situations the depressions moving towards the east encounter a high pressure ridge or a blocking anticyclone and become stationary from few hours to few days. Extreme wind events are observed during the later situation.
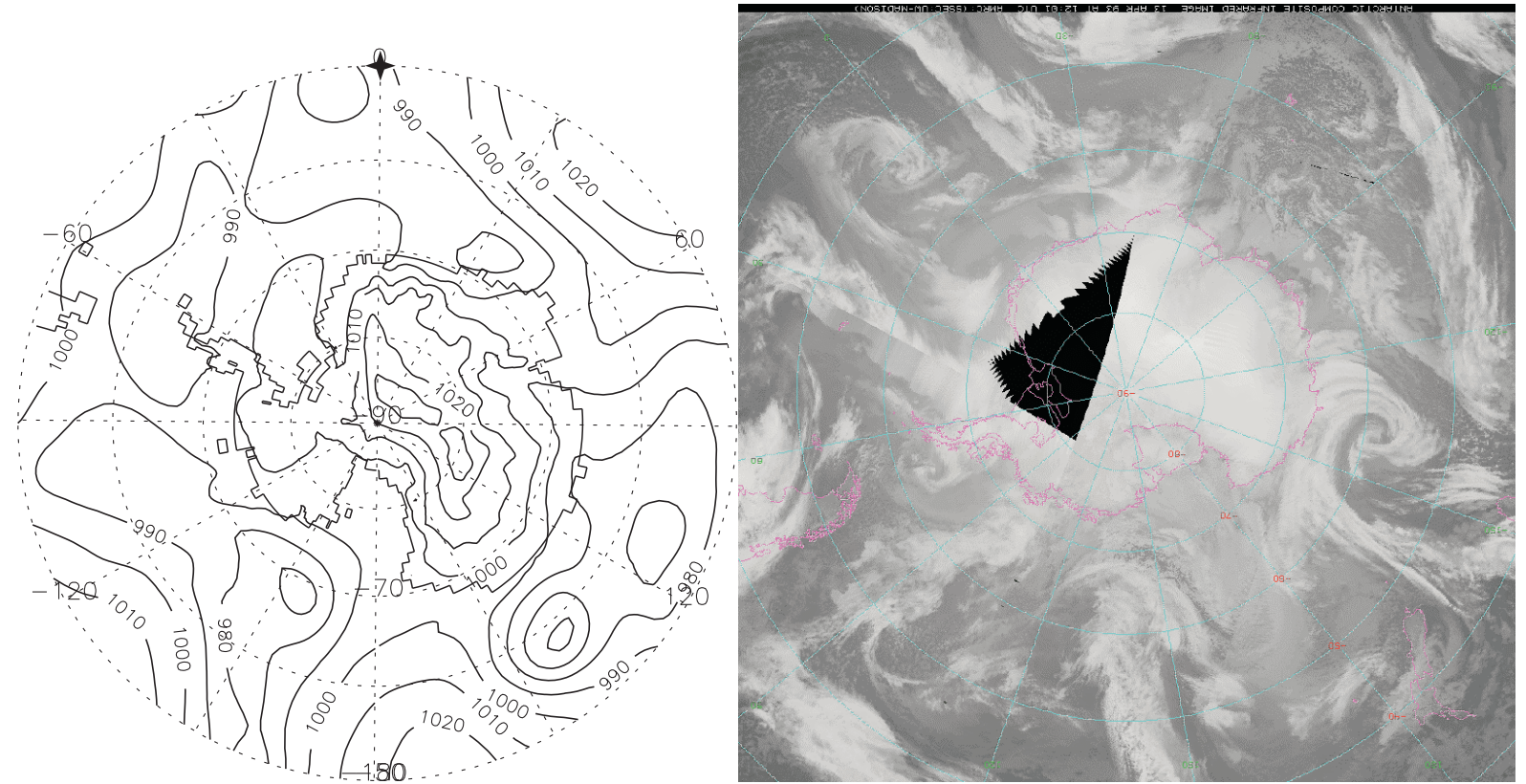

(a)

1200 h 13 April 1993

(b) 1200 h 13 April 1993

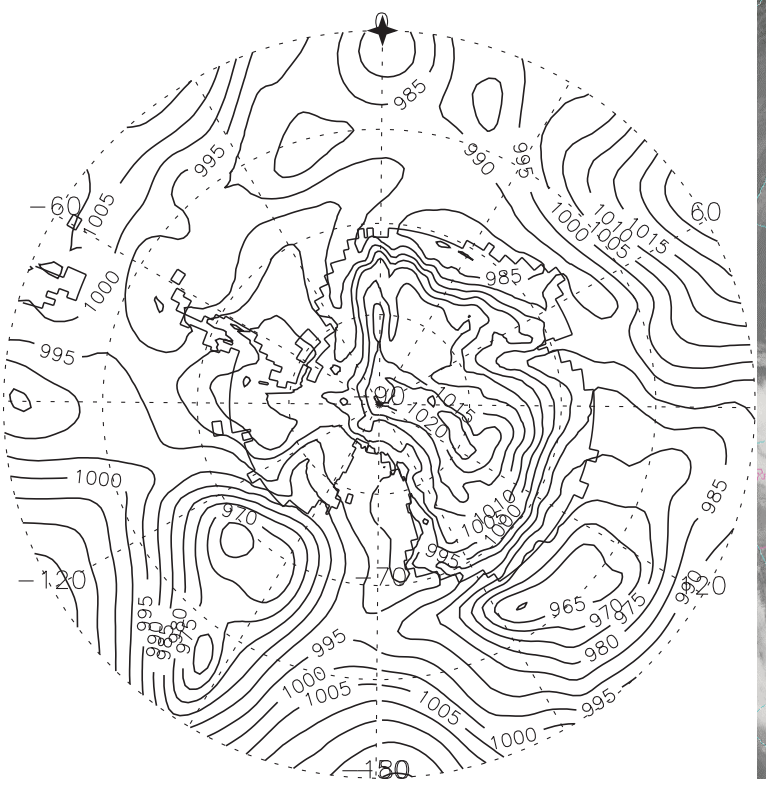

(C)

0600 h 14 April 1993

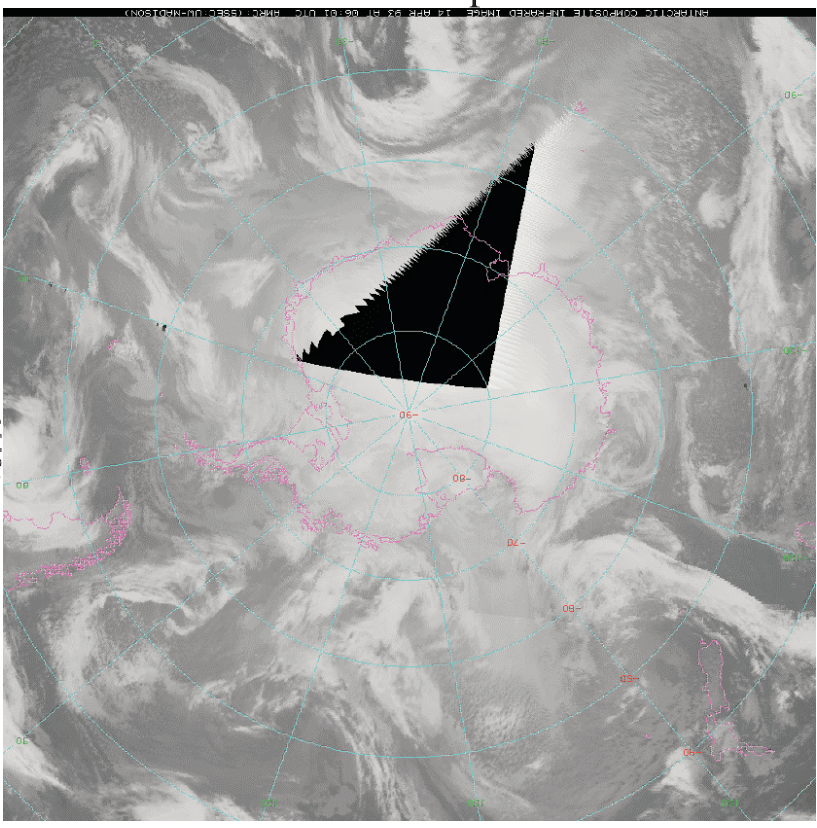

(d)

0600 h 14 April 1993

Fig. 3a-d. ECMWF analyses of mean sea level pressure charts and composite infrared satellite images for $1200 \mathrm{~h}$ 13 April (a,b) and 0600 h 14 April 1993 (c,d), respectively. 


\subsubsection{1-17 April 1993}

Figure $2 \mathrm{a}, \mathrm{b}$ shows the time series of meteorological parameters for DC and DdU for 11-17 April 1993. For convenience, time series of pressure are plotted together with the time series of temperature and horizontal wind speed. The pressure difference (dp) between DC and DdU was plotted along with the wind speed at DdU (panel 3 of fig. 2b) to show their correlation with each other. The time series (fig. 2b) show a strong wind event at DdU, where the wind remained high from 13 to 15 April, 1993 (fig. 2b). The wind at DdU started increasing as the pressure started decreasing and the dp started increasing. The wind remained high as long as the pressure remained low at DdU (fig. 2b, 13-15 April 1993).

The maximum in wind speed was observed approximately at the same time the minimum in pressure or maximum in dp occurred. The temperature at DdU increased by about 10 degrees in one day in response to high winds. After the cessation of strong winds, the temperature dropped abruptly by 10 degrees in few hours. Figure $3 a-d$ shows the MSLP charts and the composite infrared satellite images during 13 and 14 April 1993. During this event a low pressure appeared to the west of the Adelie Land coast on 13 April (fig. 3a,b). However, it could not move eastward due to the presence of an anticyclone to the northeast of the coast. Instead, the system moved southwards towards the coast and intensifyied in the process (fig. 3c,d). It remained stationary at around $62 \mathrm{~S}$ until 15 April 1993 intensifying continuously, and resumed its usual journey eastward after the high pressure ridge disappeared. Pressure difference between the continent and the coast was strengthened during this event (fig. 2b, third panel). DdU experienced strong winds (greater than $20 \mathrm{~ms}^{-1}$ with a maxima of around $40 \mathrm{~ms}^{-1}$ ) for the whole duration this low pressure system remained in the vicinity of the station. During this event, pressure at DC decreased very slowly, remained stationary for one day and then decreased again in response to another approaching system on 15th April 1993. The wind at DC, however, did not reflect any significant influence (fig. 2a). The latter system had little effect on the winds at DdU, where the winds increased only up to $15 \mathrm{~ms}^{-1}$.

\subsubsection{1-8 November 1993}

This period show two systems which passed the DdU coast (fig. 4b). The wind remained high for the whole duration the pressure remained low in both events (fig. 4b). The correlation between the time series of pressure and wind was negative even at DC (fig. 4a). We will discuss the second system, which had its effect on wind at DdU for approximately 4 days, from 4 November to 8 November 1993. A depression started approaching the coast on 4 November (fig. 5a,b) and the winds at DdU increased (fig. 4b). The system moved past the coast after 6 November 1993 (fig. 5c,d), but remained in the vicinity untill $0600 \mathrm{~h}, 8$ November 1993 and continued to influence strong winds at DdU. The pressure remained around $967 \mathrm{hPa}$ for
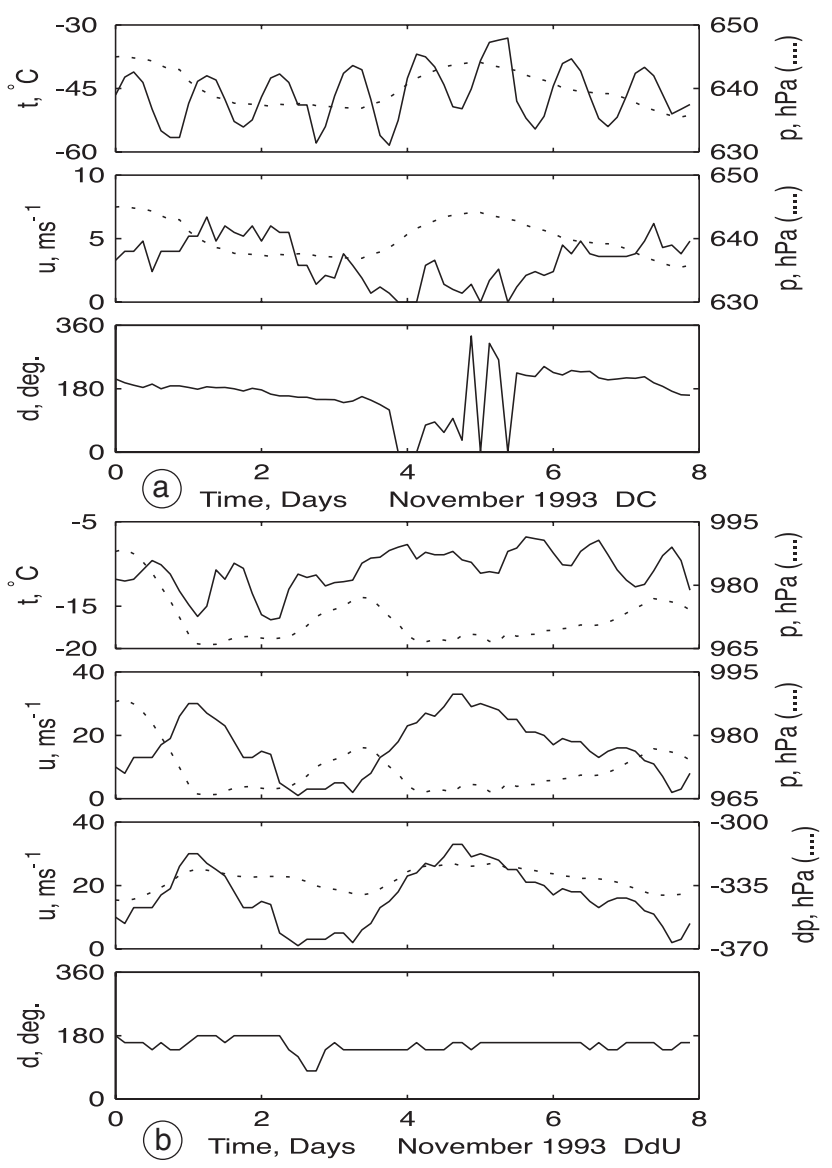

Fig. 4a,b. Time series of meteorological parameters: a) for Dome C; b) for Dumont d'Urville depicting strong wind events around 1 November and from 4 to 7 November 1993, respectively. 


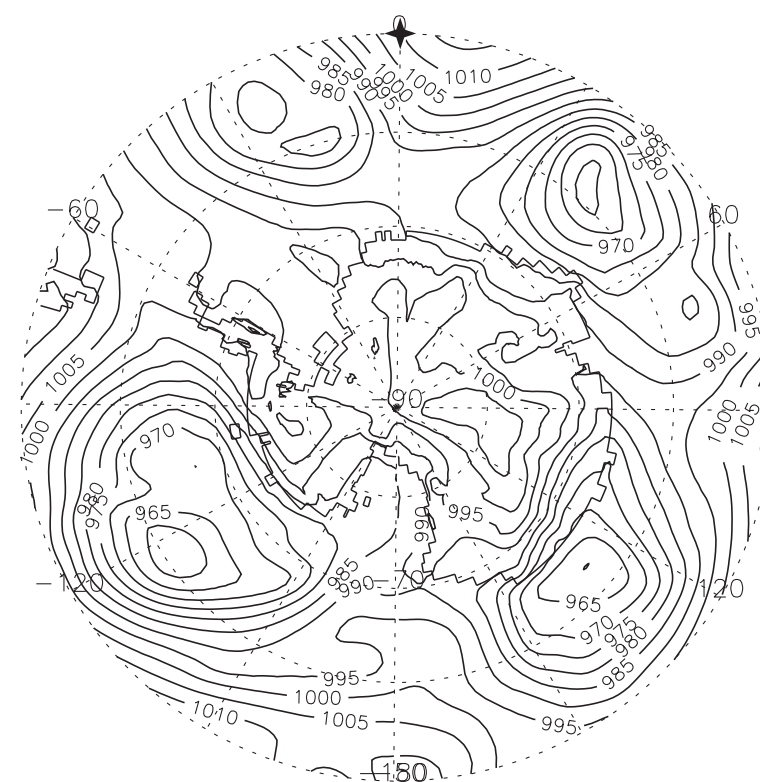

(a)

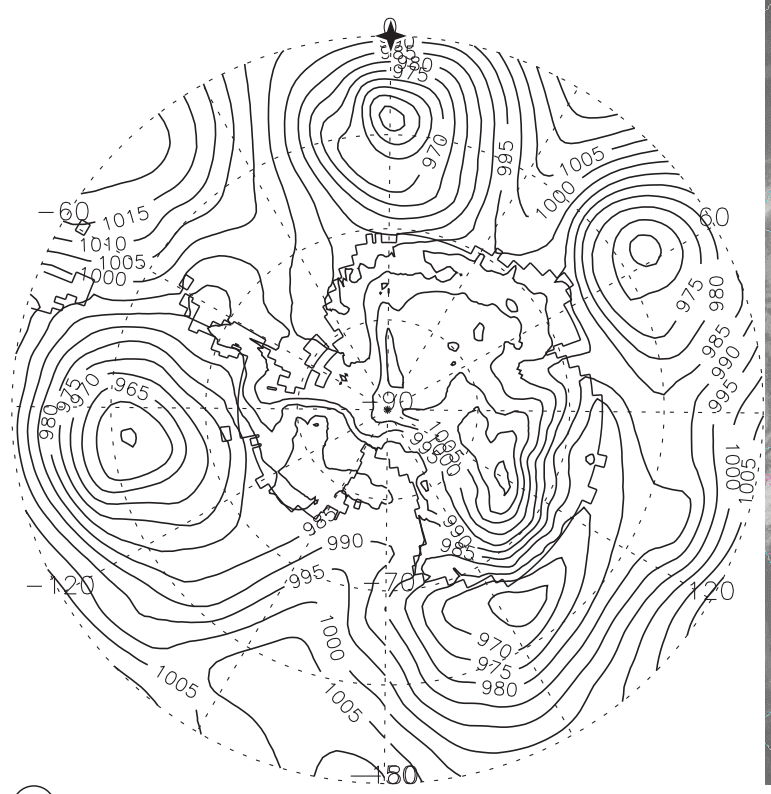

(C)

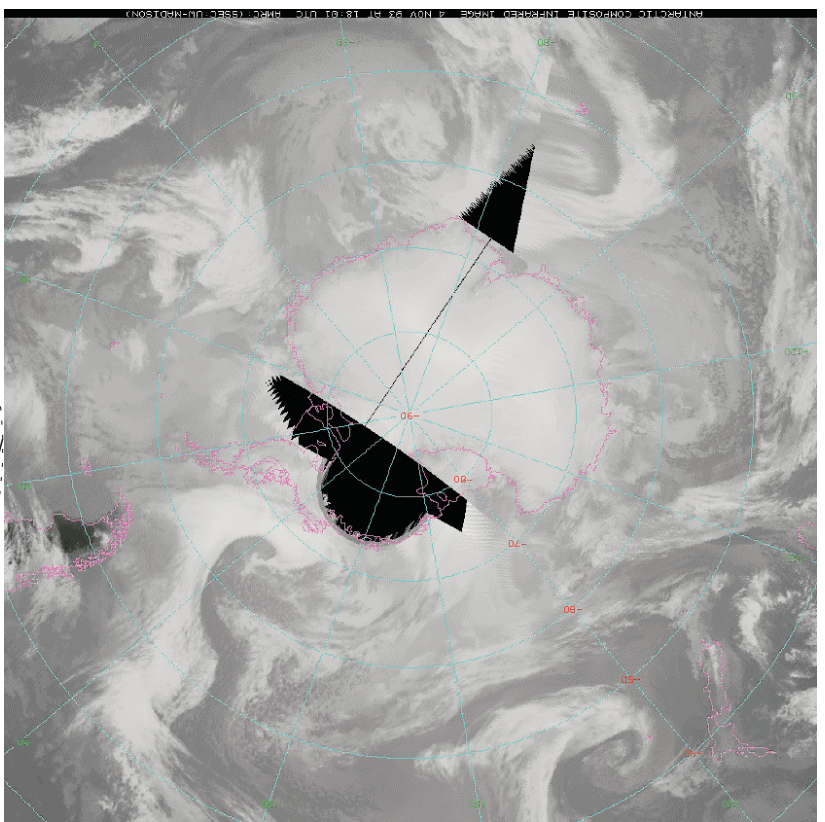

(b) $\quad 1800$ h 4 November 1993

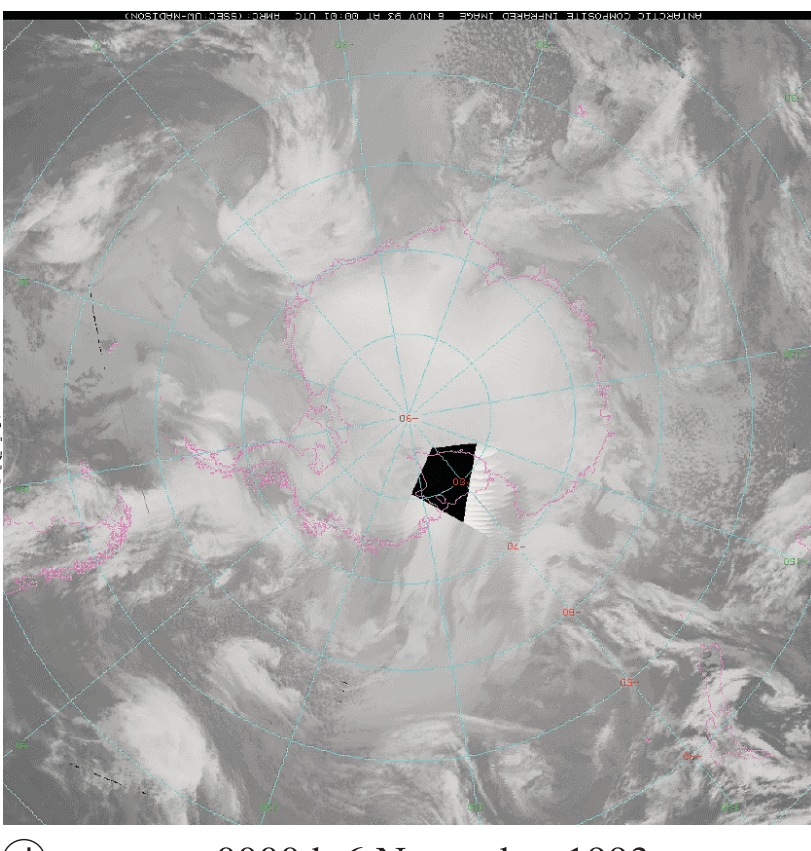

(d)
0000 h 6 November 1993

Fig. 5a-d. ECMWF analyses of mean sea level pressure charts and composite infrared satellite images for 1800 h 4 November (a,b) and 0000 h 6 November 1993 (c,d), respectively.

approximately 3 days at DdU (5-7 November 1993, fig. 4b) and increased gradualy thereafter. The strong winds even after the passage of the depression to the east, were due to the pressure difference, dp, which continued to be high (fig. 4b, third panel) and which could sustain high winds for longer duration. The depression was made stationary in its usual eastward track by the blocking high pressure ridge to the northeast of the coast. However, the depression did not move inland, in spite of the high pressure ridge to the northeast. This is, once again, envisaged as due 
to high dp. The temperature at DdU, although depicted a diurnal variation, remained high. At $\mathrm{DC}$, the response in pressure was delayed and it decreased continuously from 5 November onwards. The winds at DC increased to $7 \mathrm{~ms}^{-1}$ as the pressure started decreasing.

The continuously strong winds at DdU for approximately four days, can be regarded as due to the presence of an intense depression offshore in the vicinity of DdU, which maintained a high downslope pressure difference, dp. The depression helped in converging and raising the accumulating air mass near the coast, with sourtherly flow at higher levels and subsequent, subsidence over Antarctica. This provided a faster replenishment of the air mass at the plateau for the drainage to be stronger and longer lasting.

\subsection{Lows penetrating into the interior}

In this category there are again two possibilities - the lows penetrating inland from the west or from the east of the site.

\subsubsection{8-18 July 1993}

The time series in fig. 6a,b show three systems which passed the Adelie Land coast. The first two successive depressions passing at short intervals of time had their distint influence on wind at DdU (fig. 6b, centered around 10 and 12 July 1993). The lowering of pressure at DC was also accompanied by high winds and high temperature during these events (fig. 6a, around 10 and 15 July 1993). On 11 July 1993 (fig. $7 a, b)$, much of the coastal area was under the influence of the low pressure. This influenced strong winds at DC also and the temperature at DC rose by 20 degrees. At DdU, this first system had a good negative correlation with wind and the temperature increased by 15 degrees within a day. The wind at DdU came down once the system penetrated inland and had its influence in the interior on 11 July 1993.

During the second event, the wind at DdU returned to normal even before the minimum in pressure was reached (fig. 6b, around 13 July

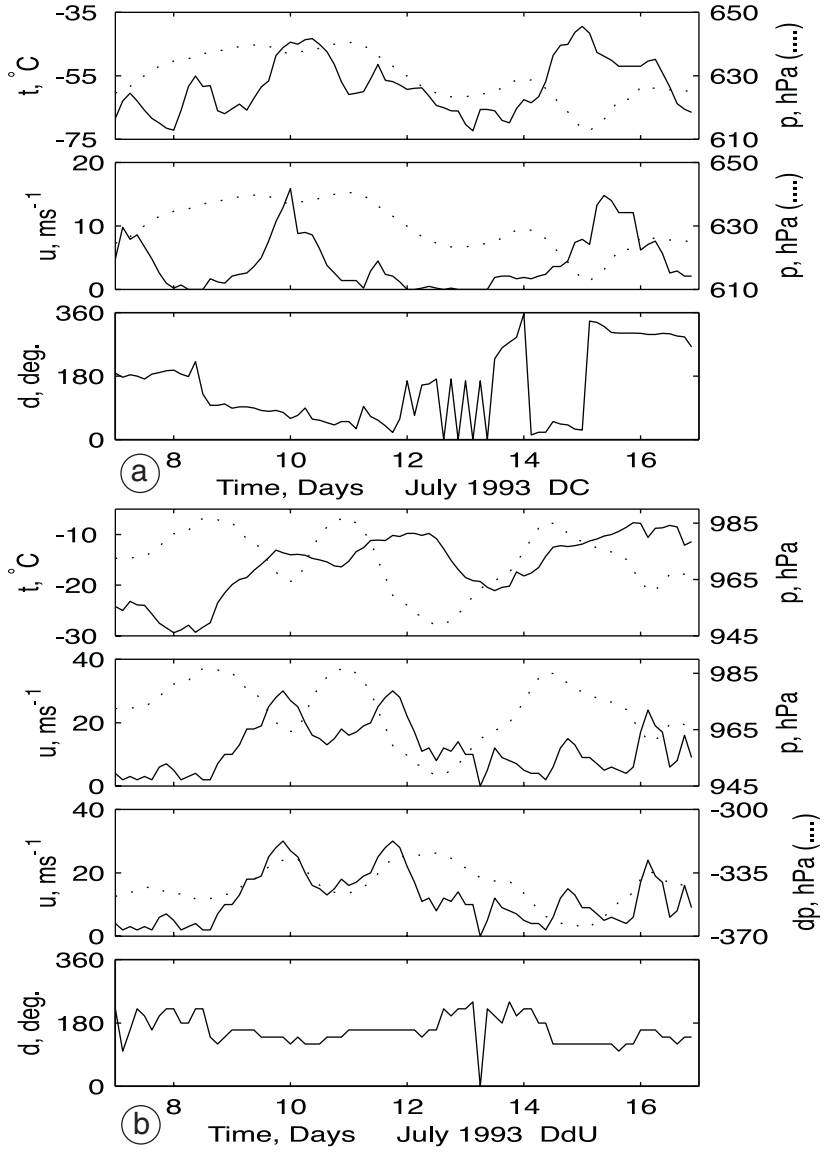

Fig. 6a,b. Time series of meteorological parameters: a) for Dome $\mathrm{C}$ showing strong wind events around 10 and 15 July 1993; b) for Dumont d'Urville depicting strong wind events around 10 and 12 July 1993, respectively.

1993), although the dp was high. On 12 July 1993 three small vortices moving towards the Adelie Land coast were blocked by an anticyclonic ridge (fig. 7c,d). The three vortices merged and the resulting system moving eastward penetrated inland from the east of DdU (fig. 7e,f). Its influence started diminishing after the system moved past the DdU coast, although the pressure at DdU remained low. The short duration of this wind event could be due to the penetration of the depression inland.

On 16 July 1993, another depression started penetrating into the continent from around $120 \mathrm{E}$ due to the presence of a high pressure centre to the east near the Adelie Land coast (fig. 7g,h). During this event the dp was very low (fig. 6b). The centre of the depression started enlarging and disintegrated into two small systems, with one 


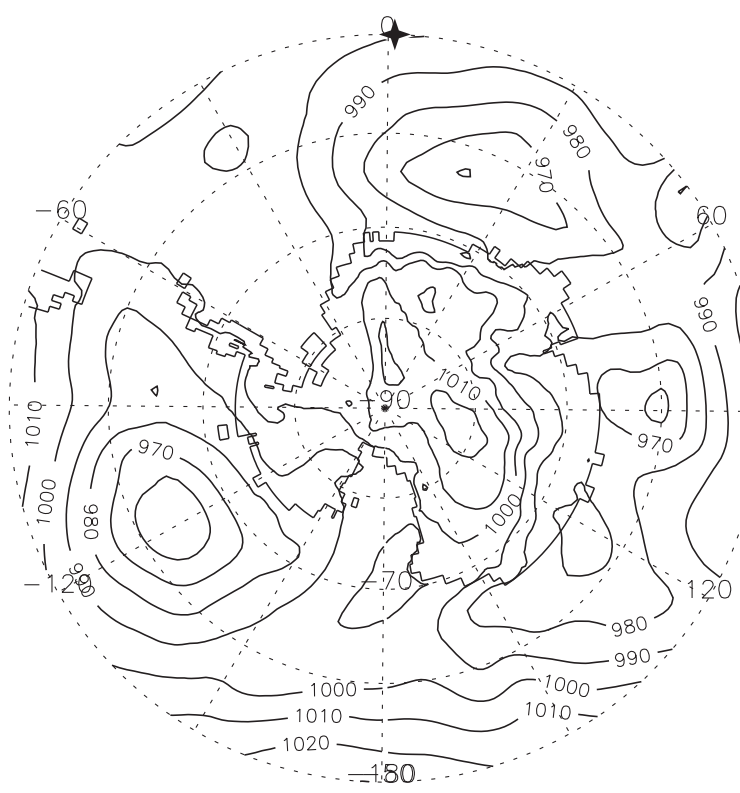

(a)

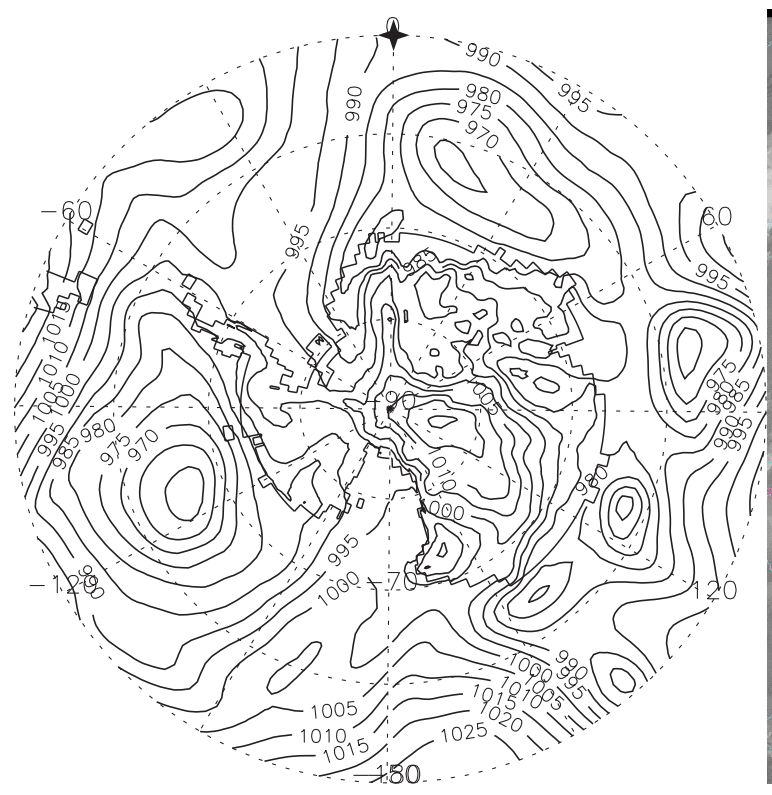

(C)
0000 h 12 July 1993

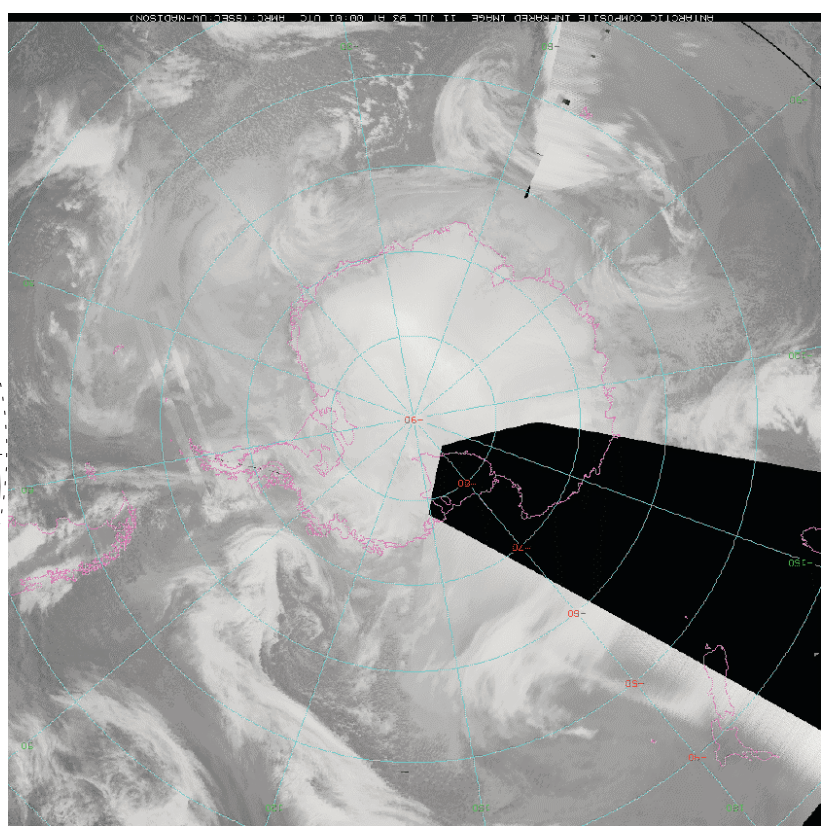

(b) $\quad 0000$ h 11 July 1993

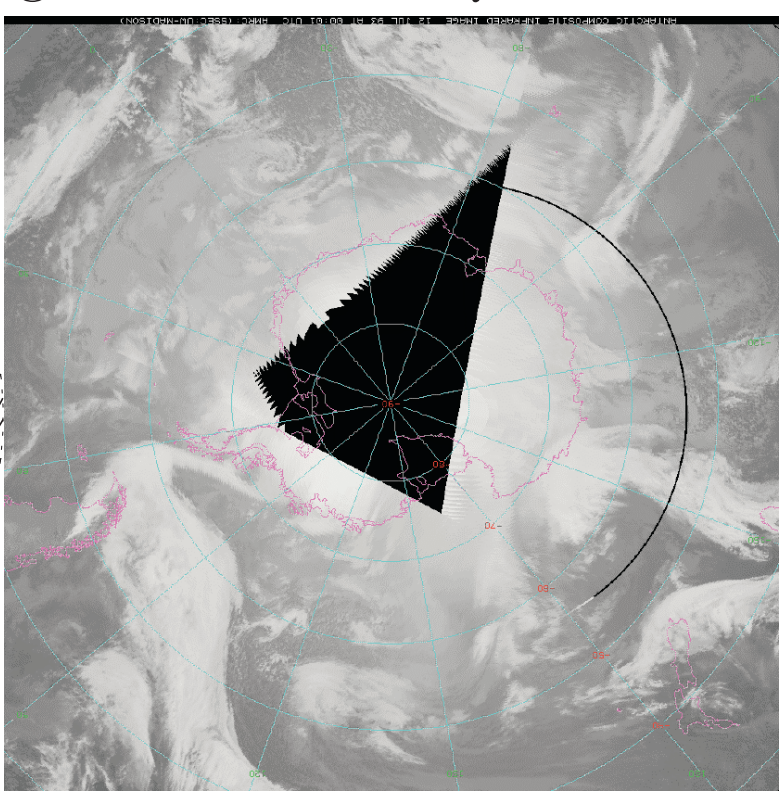

(d)

Fig. 7a-d. ECMWF analyses of mean sea level pressure charts and composite infrared satellite images for 0000 h 11 July (a,b) and 0000 h 12 July 1993 (c,d), respectively.

centre lying in the interior and the other over the ocean. The one in the interior at around 70S, 100E filled up fast and the other on the ocean at around 58S, 100E continued its march southeastward. The winds at DC remained high $\left(>10 \mathrm{~ms}^{-1}\right)$ as long as the effect of the low pressure system was felt at the station (fig. 6a), while the winds at DdU were not enhanced due to low dp. Later, a shallow low pressure system approaching the Adelie Land coast from around 58S, 130E on 17 July 1993 had a short-lived influence on pressure and wind at DdU. The fall in pressure was 


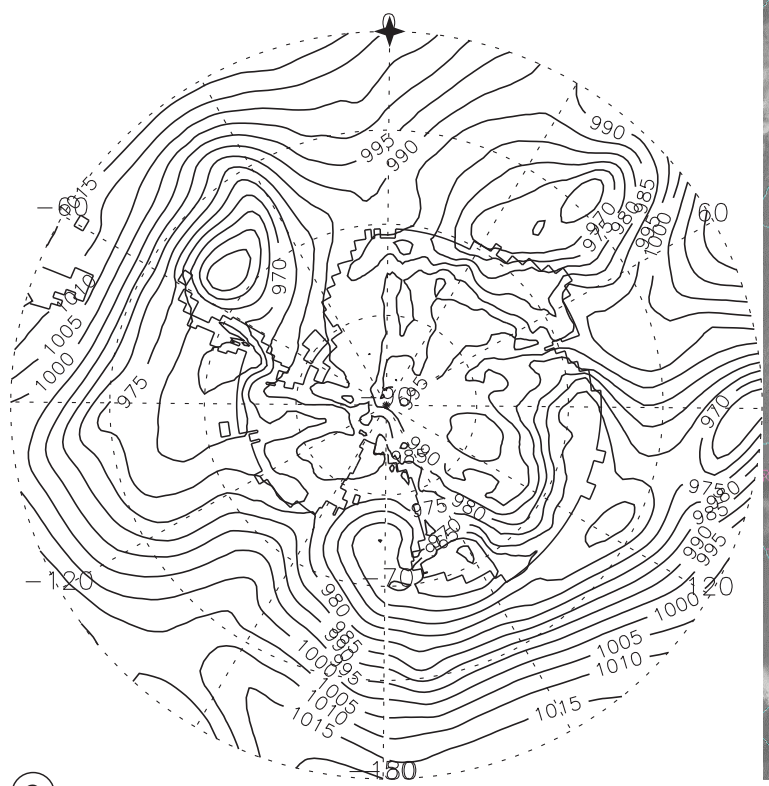

(e)

1800 h 13 July 1993

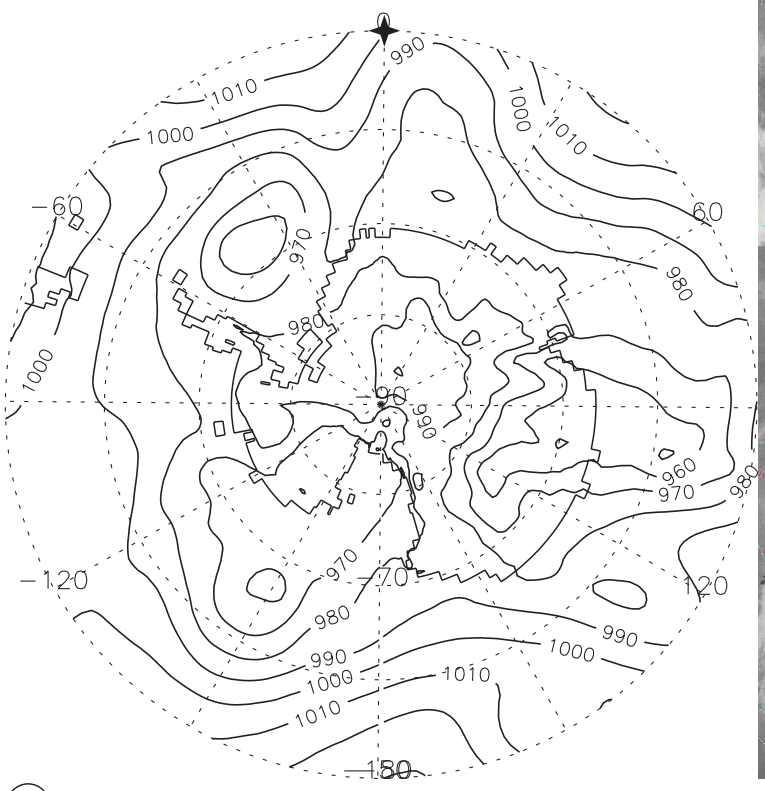

(9)

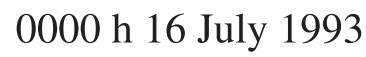

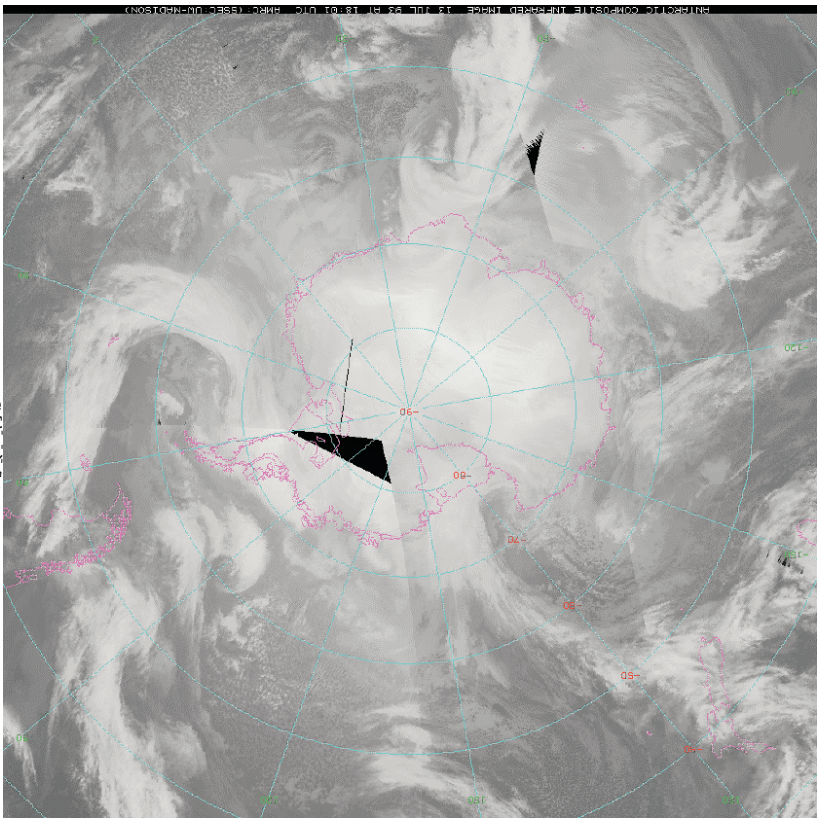

f 1800 h 13 July 1993

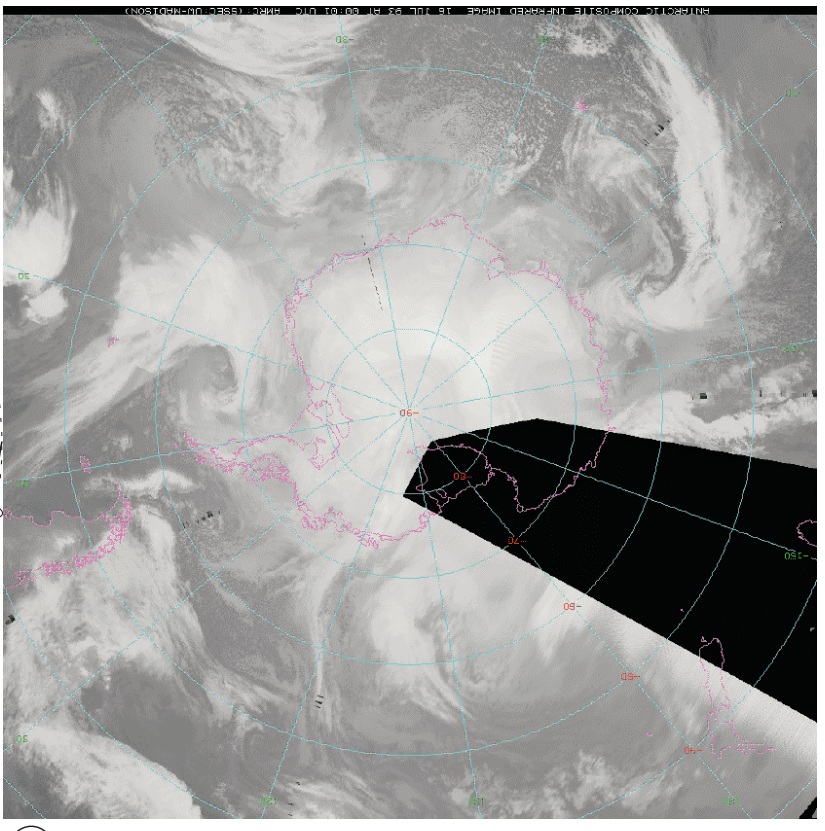

(h)

Fig. 7e-h. ECMWF analyses of mean sea level pressure charts and composite infrared satellite images for 1800 h 13 July (e,f) and 0000 h 16 July 1993 (g,h), respectively.

steep on 17 July 1993 (fig. 6b). The influence on wind, likewise, was relatively pronounced for this later steep pressure fall period, when it showed a small peak. Initially the slow and gradual pressure decrease could not sustain stronger winds due to very low dp.

\subsection{2. $17-22$ September 1993}

The time series for this event at DdU show one depression which passed its coast around 19 September 1993 (fig. 8b). The wind came down to the initial value much before, even 


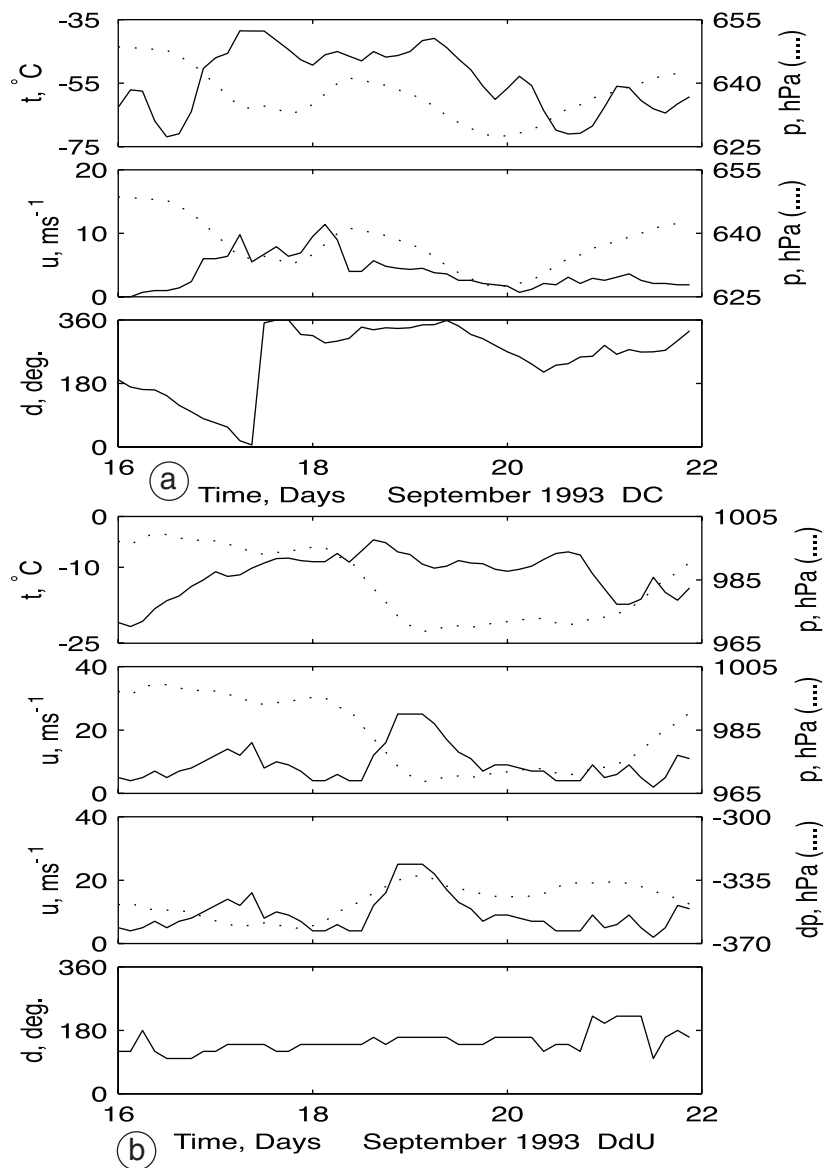

Fig. 8a,b. Time series of meteorological parameters for: a) Dome $\mathrm{C}$ showing strong wind event around 18 September 1993; b) Dumont d'Urville depicting strong wind event around 19 September 1993, respectively.

though the pressure remained continuously stationary at a low value for three days (fig. 8b, 19-21 September 1993). The wind came down due to decreased dp. Pressure started falling at DdU on 19 September 1993 (fig. 8b) with the approach of the depression (fig. 9a,b) and dp started increasing. Winds at DdU likewise increased due to increasing dp. Next day, much of the East Antarctic coastal stretch including the interior was influenced by a trough of low pressure (fig. 9c,d). Due to this, the station level pressure at DdU (fig. 8b) remained more or less constant for almost three days, before rising to the initial value after 22 September 1993 (fig. 8b). The dp decreased as the depression influenced the interior on 20 September 1993, ceasing strong winds. The temperature started increasing at DdU on 19 September 1993 with increasing winds and remained high for the whole duration until the pressure started increasing once again. The persistence of high temperatures, even after the wind slowed down, could be due to the clouds or marine air advection above the boundary layer. At DC (fig. 8a), the decreasing pressure during this event had no influence on surface winds.

The pressure decrease around 17-18 September 1993 at DC (fig. 8a) was in response to a low pressure system which penetrated far into the interior from the west of DdU. This system started penetrating from around $130 \mathrm{E}$ on 17 September 1993. Figure 9e,f shows the MSLP charts and the composite infrared satellite images for $0000 \mathrm{~h} 18$ September 1993. This depression moved westward after it penetrated inland. The wind at DC increased in response to the penetration of this system. This system had very little influence on the pressure and wind at DdU. However, temperature at DdU increased, which might be due to the clouds advected ahead of this system (Naithani et al., 2002).

\subsubsection{6-18 December 1993}

The time series for this period show (fig. $10 \mathrm{a}, \mathrm{b})$ diurnal variation in wind due to the diurnal variation in temperature, along with the incidences of strong wind events associated with sharp pressure changes. The diurnal cycle in wind which can be considered to be due to a pure katabatic component, in the large and small hours of the day, rarely exceeds $5 \mathrm{~ms}^{-1}$ at DC and $10 \mathrm{~ms}^{-1}$ at DdU. The wind during the steep pressure changes associated with the approach of a depression towards the Adelie Land coast, are higher than 10 and $20 \mathrm{~ms}^{-1}$ at DC and DdU, respectively (fig. $10 \mathrm{~b}$, around 10,12 and 15 December 1993). This time series also show a peculiar case at DdU when the wind had two distinct peaks during the time the pressure was changing (fig. 10b, around 15 December 1993). The first peak in the wind was observed when the pressure was decreasing, while the second peak was observed when the pressure started increasing back to normal. The time series of wind at DC (fig. 10a) showed a clear distinct wind peak during the passage of this system, whereby wind increased to higher than $12 \mathrm{~ms}^{-1}$. The 


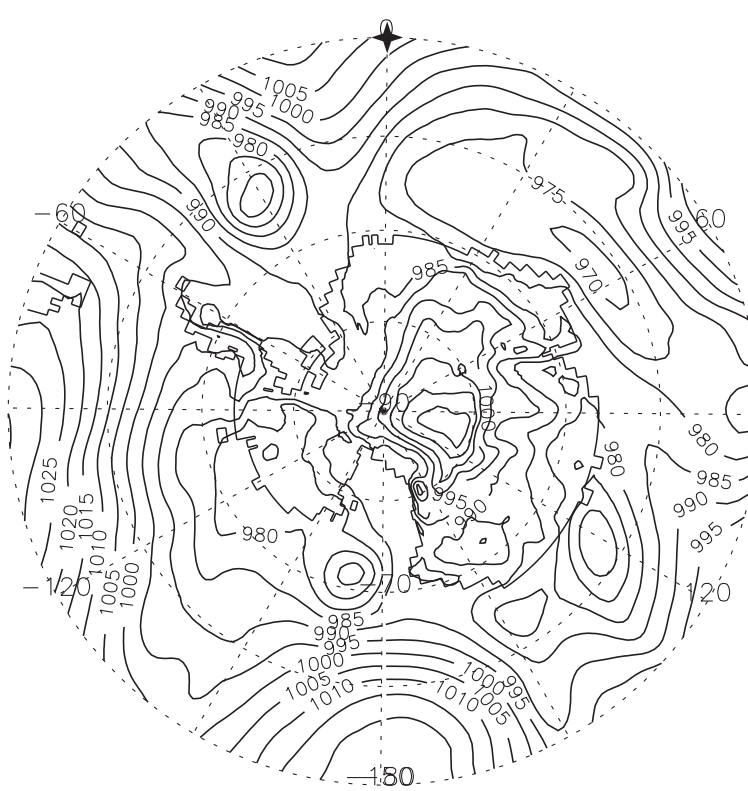

(a)

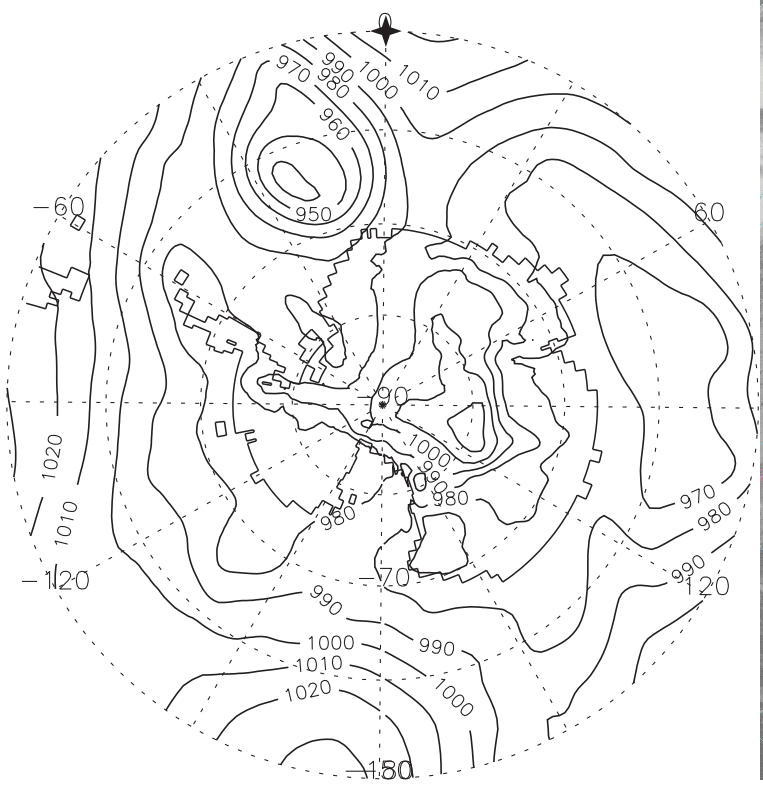

(C) $\quad 0000 \mathrm{~h} 21$ September 1993

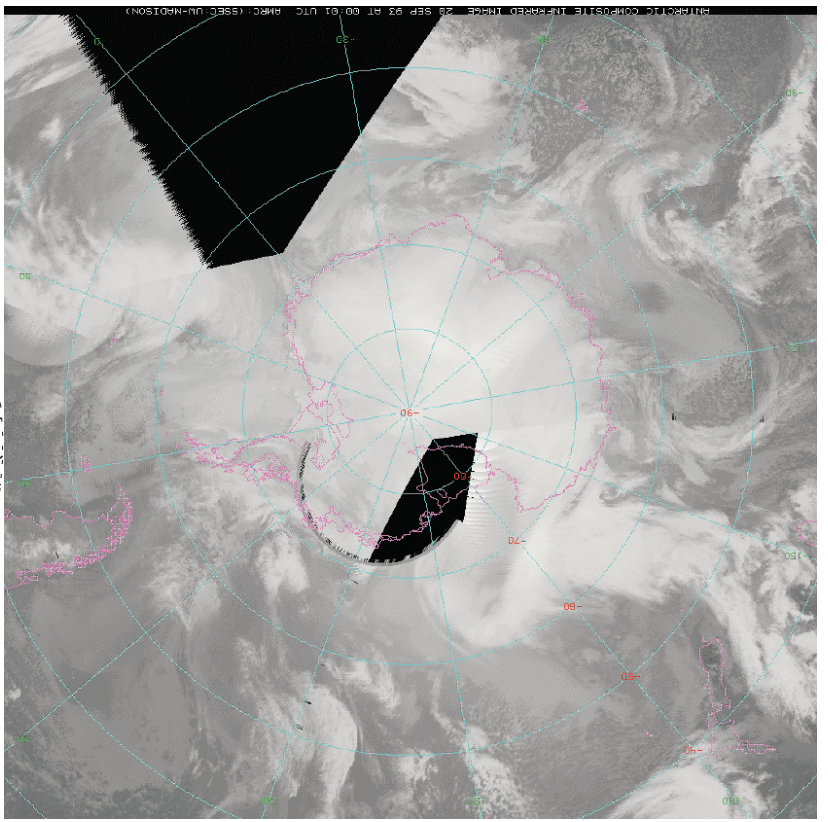

(b) $\quad 0000 \mathrm{~h} 20$ September 1993

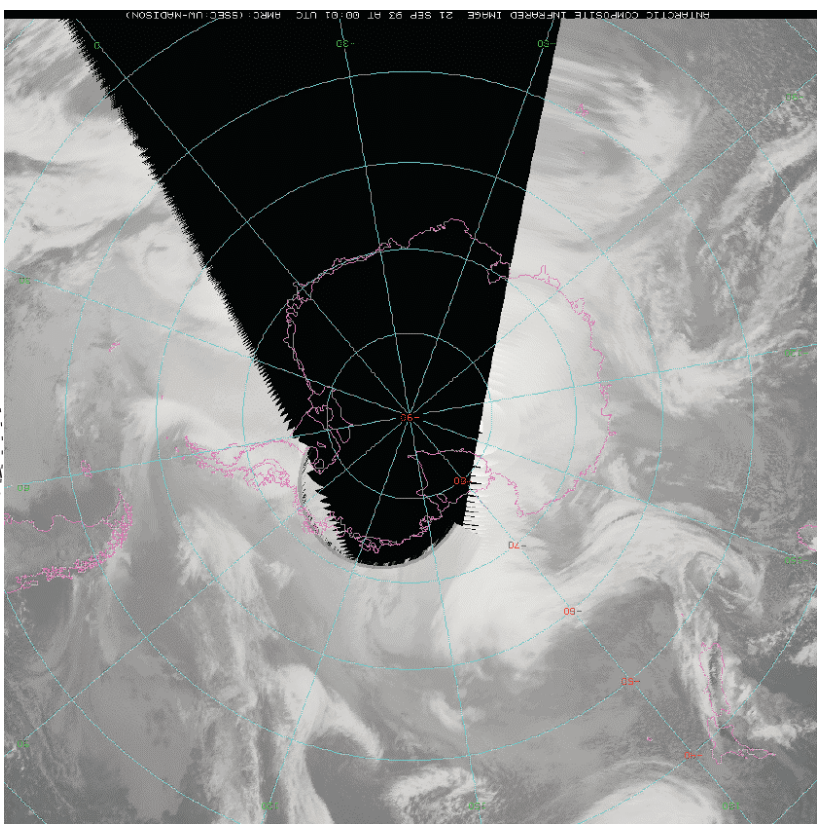

(d) $\quad 0000 \mathrm{~h} 21$ September 1993

Fig. 9a-d. ECMWF analyses of mean sea level pressure charts and composite infrared satellite images for 0000 h 20 September (a,b) and 0000 h 21 September 1993 (c,d), respectively.

temperature at both sites increased in response to the increasing winds. A low pressure system approached the coast on 15 December 1993 from northwest and intensified in the process (fig. 11a,b). Once near the Adelie Land coast to the east of DdU (centered at $65 \mathrm{~S}$ and $150 \mathrm{E}$ ), its movement further east was hampered by the high pressure ridge situated to the east of the site. The low pressure system became slow-moving, intensified and started penetrating inland after 1200 h, 16 December 1993 (fig.11c, d). At 0000 h next day (fig. 11e,f), its elongated centre was 


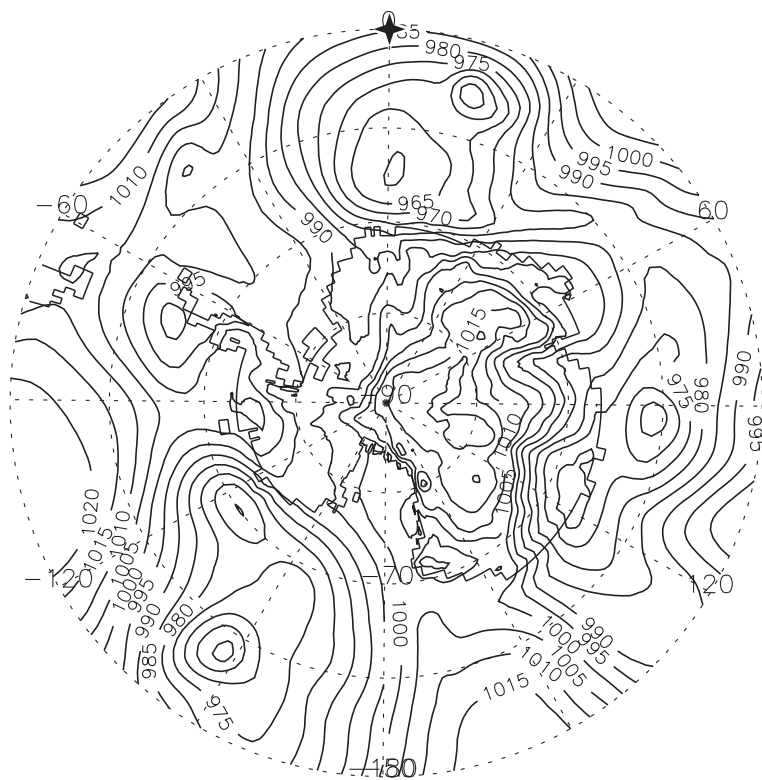

(e) $\quad 0000 \mathrm{~h} 18$ September 1993

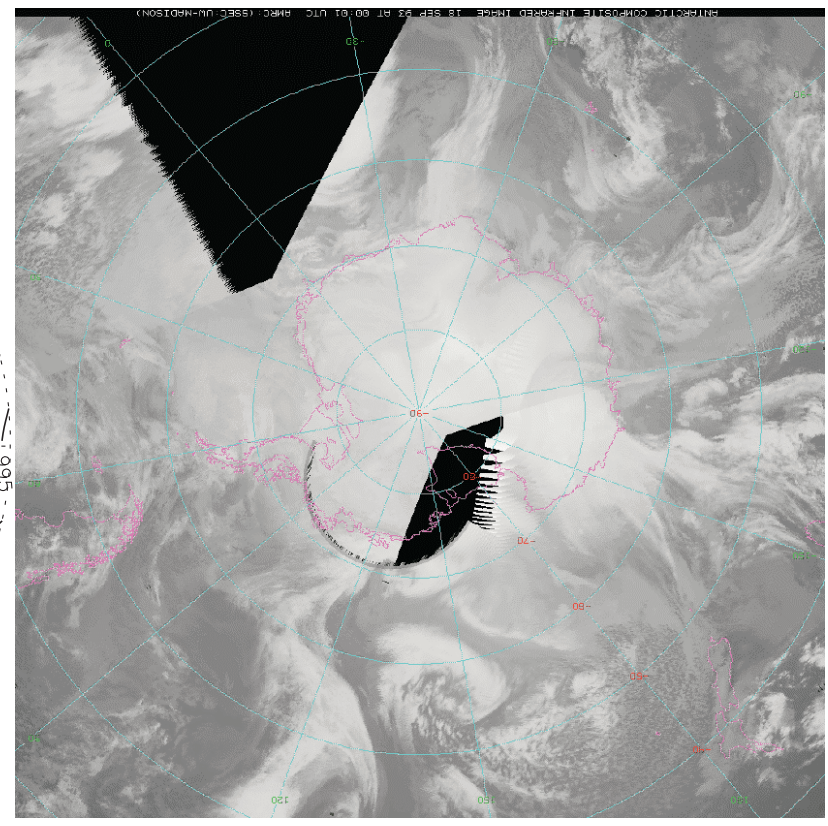

f $\quad 0000 \mathrm{~h} 18$ September 1993

Fig. 9e,f. ECMWF analysis of mean sea level pressure chart and composite infrared satellite image for $0000 \mathrm{~h}$ 18 September 1993.

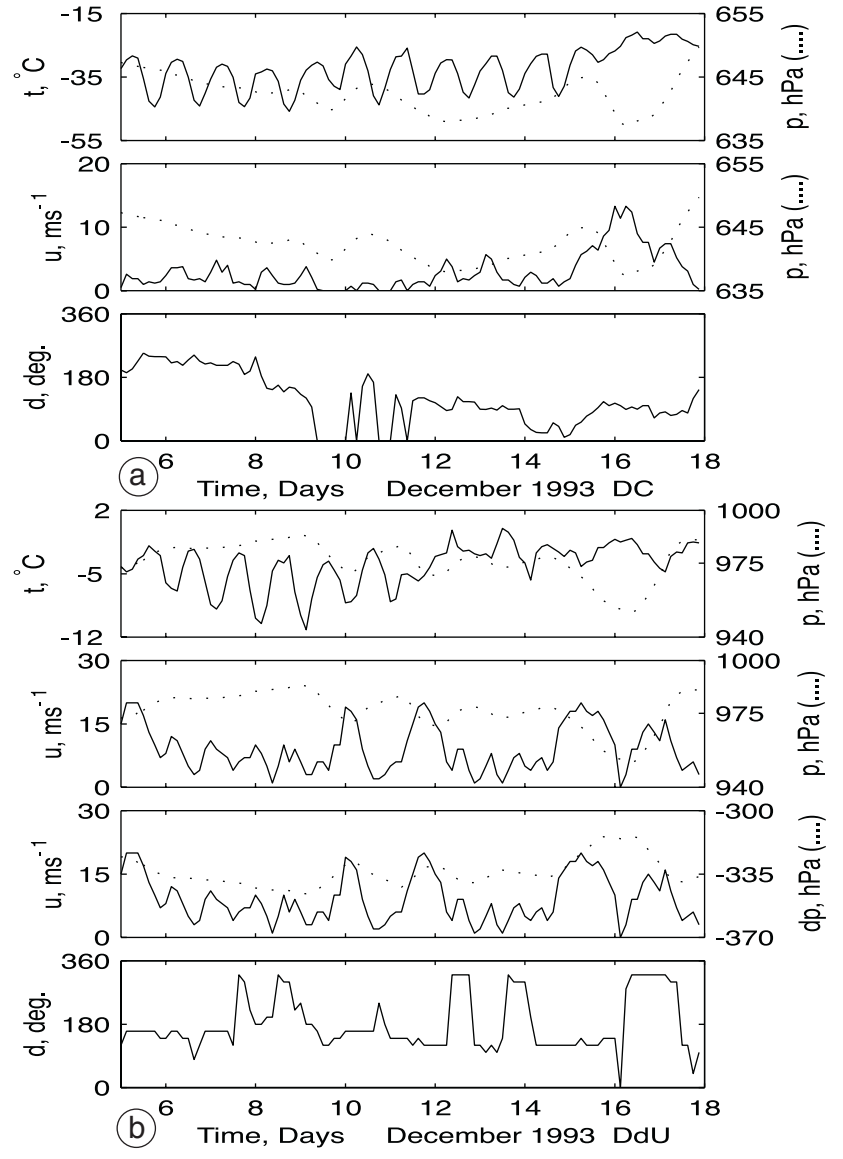

seen over much of the interior. Winds at DdU increased to around $20 \mathrm{~ms}^{-1}$ and were from SE for the time this low pressure system was approaching the DdU coast from the northwest and the dp was increasing (fig. 10b). Winds came down abruptly once the system started penetrating inland at around $0000 \mathrm{~h}$ on 17 December 1993. At the point the low pressure system started moving further south from DdU (fig. 11e,f), station level pressure started increasing in response. The wind changed direction, became northeasterly and increased to about $15 \mathrm{~ms}^{-1}$. Once the pressure at DdU estabilised back to its initial value at around 0600 h, 18 December 1993, the wind decreased and became southeasterly. Winds at DC remained high as long as the pressure was

Fig. 10a,b. Time series of meteorological parameters: a) for Dome $\mathrm{C}$ showing a strong wind event around 16 December 1993; b) for Dumont d'Urville depicting strong wind events around 10,12, 15 and 17 December 1993, respectively. 

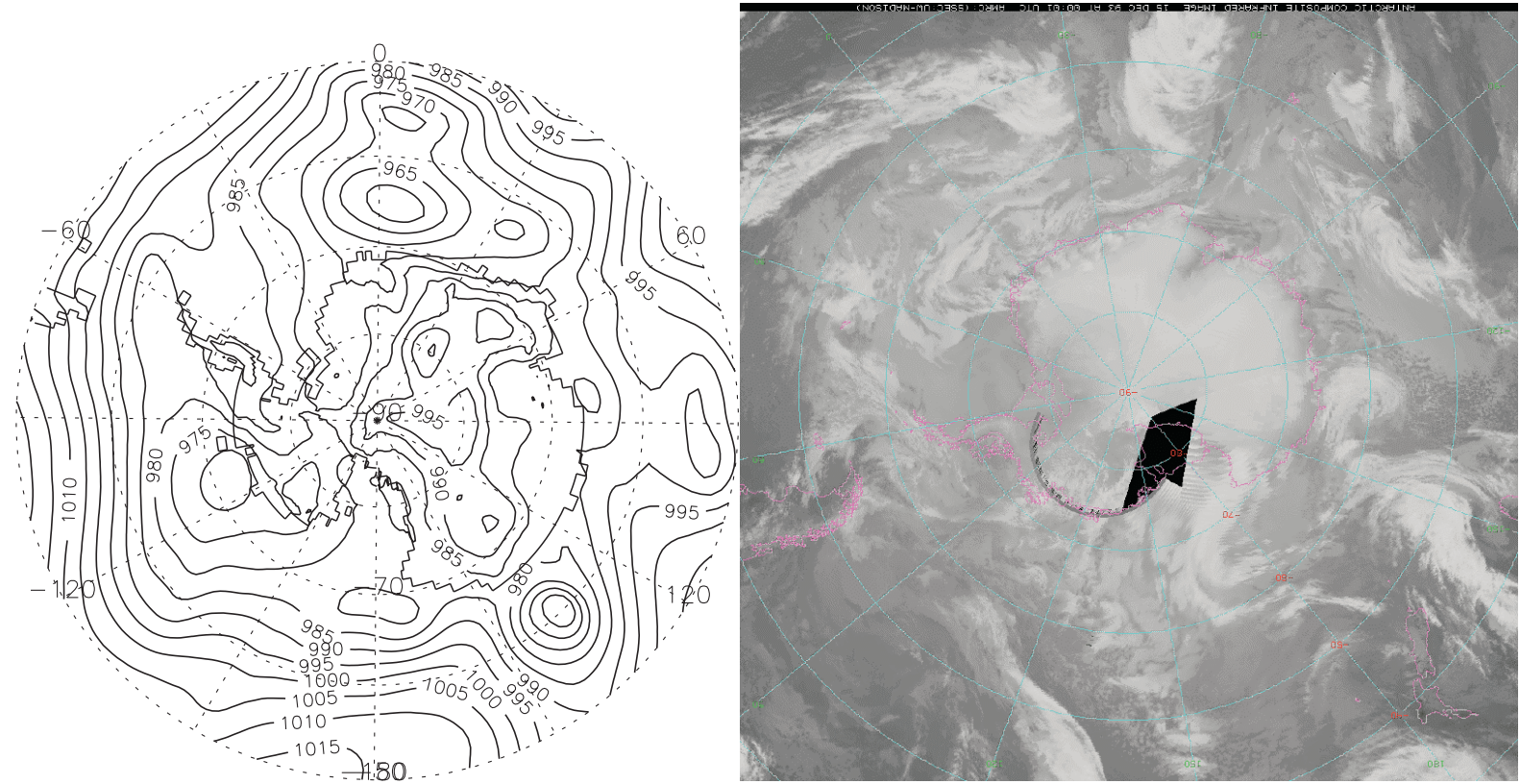

(a)

0000 h 15 December 1993

(b)
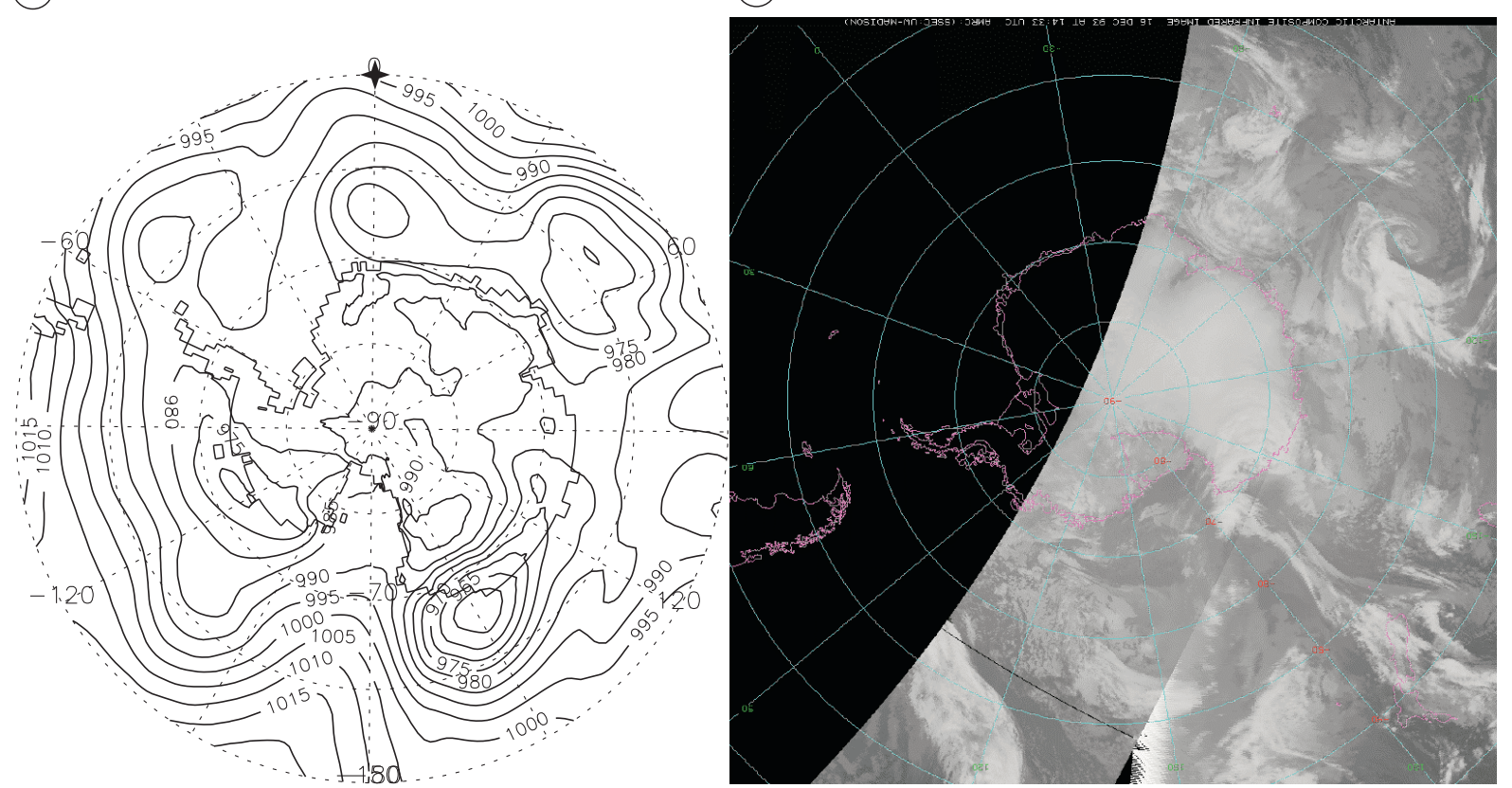

1200 h 16 December 1993

(d)

1433 h 16 December 1993

Fig. 11a-d. ECMWF analyses of mean sea level pressure charts and composite infrared satellite images for 0000 h 15 December (a,b) and 1200 h 16 December 1993 (c,d), respectively.

changing (fig. 10a). This system could penetrate inland on account of the high pressure ridge to the northeast of Adelie coast.

Looking into the time series of the station level parameters, pressure in particular, it is difficult to see in which direction the system went! Under normal conditions a depression moves in the eastward direction. The pressure at the station shows a decreasing trend until the depression approaches the station and an increasing trend afterwards, once it moves past the station. On this particular occasion, the 


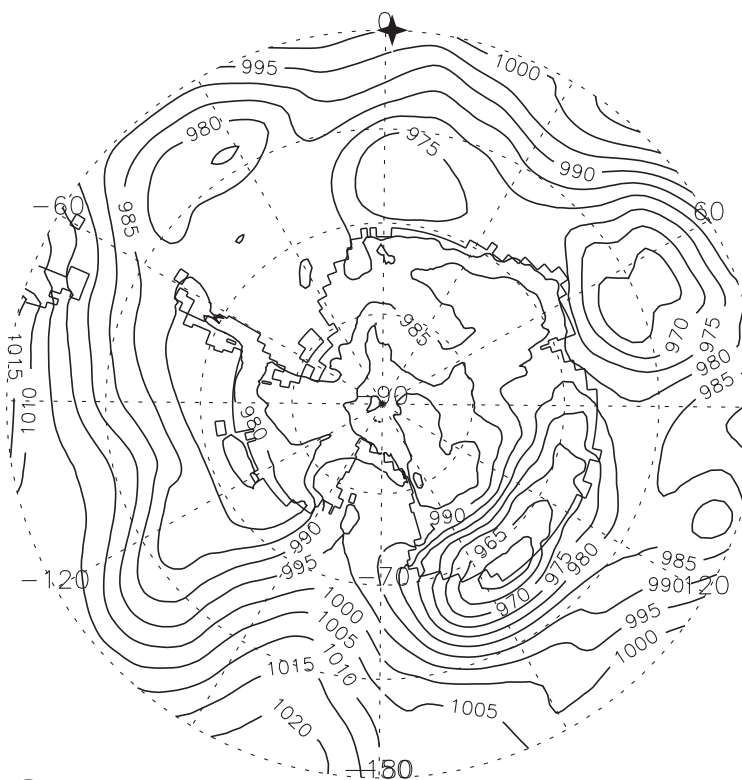

(e)

0600 h 17 December 1993

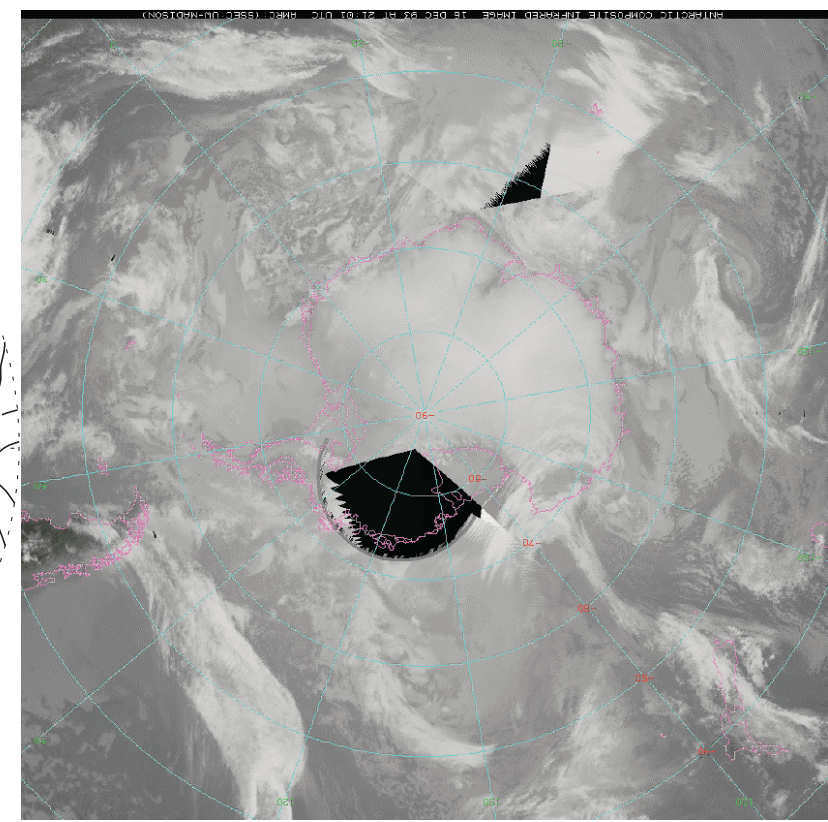

f $\quad 2101 \mathrm{~h} 17$ December 1993

Fig. 11e,f. ECMWF analysis of mean sea level pressure chart and composite infrared satellite image for $0600 \mathrm{~h}$ 17 December 1993.

system moved eastward first and then southwestward into the interior, after it moved past DdU. Pressure at DdU started increasing as the centre of the depression moved further inland. The station level pressure recording is similar to what happens when the system moves past the DdU coast in its usual motion eastward. In any case, this interpretation would be dificult to ascertain without the help of pressure charts and satellite images.

\section{Discussion and conclusions}

The strong wind events observed during the year 1993 at DdU and DC were analysed, using MSLP charts and composite infrared satellite images, to determine the position of the depression with respect to the coast during the event. The time series of wind and pressure and the MSLP charts and composite infrared satellite images during the strong wind events indicate that strong winds are associated with a decrease in pressure and increase in dp, during the approach of a depression from the west towards the Adelie Land coast, as reported in some of the earlier studies. From this study, it is inferred that the wind speed at DdU remains high as long as the pressure system remains in the vicinity and the pressure difference between the coast and inland remains high. The wind speed starts decreasing once the depression moves past the coast to the east of the station or starts penetrating inland. The penetration of the depression inland has been observed to be due to the presence of a blocking anticyclone or a high pressure ridge to the northeast of the Adelie Land coast and lower values of pressure difference between the coast and inland. The inland penetration of the depression from this part of the coastline is somewhat unusual due to steep topography. Due to the general topography and large elevation, the influence of approaching depressions in enhancing wind is seen more on the coastal station-DdU, while at DC the effect is usually not present. However, there are instances when the wind increased to above $15 \mathrm{~ms}^{-1}$ at DC due to the penetration of the depresion inland. The strong wind events at both the sites are accompanied by an increase in temperature by as high as 15 degrees at DdU and 30 degrees at DC. The temperature increase can also be due 
to the marine air intrusion and the advection of clouds ahead of the depression, apart from the wind induced vertical mixing (Naithani et al., 2002). However, in the present study no attempt has been made to study the marine air intrusion and clouds. Temperature increase with strong katabatic winds have also been reported by Parish et al. (1993) and Argentini et al. (2001). Forecasting of strong wind events is very important for helicoptor operations and field measurements in Antarctica.

\section{Acknowledgements}

This work is part of the European Commission project for Ice Coring in Antarctica (EPICA). One of the authors (JN) is thankful to the Belgian Ministry of Science Policy for giving the opportunity to work in this project. The meteorological data have been downloaded from the web sites of the University of Wisconsin and British Antarctic Survey. Sincere thanks to Matthew Lazzara of the University of WisconsinMadison for providing the composite infrared satellite images. The MSLP pressure charts are obtained from the ECMWF archives.

\section{REFERENCES}

Argentini, S., I.V. Petenko, G. Mastrantonio, V.A. BEZVERKHNII and A.P. Viola (2001): Spectral characteristics of East Antarctica meteorological parameters during 1994, J. Geophys. Res., 106 (D12), $12,463-12,476$

BALL, F.K. (1960): Winds on the ice slopes of Antarctica, in Proceedings of the Symposium "Antarctic Meteorology», Melbourne, February 1959 (Pergamon Press, New York), 9-16.

EGGER, J. (1985): Slope winds and the axisymmetric circulation over Antarctica, J. Atmos. Sci., 42, 18591867.

KIDSON, E. (1946): Discussion of observations at Adelie Land, Queen Mary Land, and Macquarie Island, Austr. Ant. Exp. 1911-1914, Scient. Rep. Ser. B, vol. 6.

LOEWE, F. (1974): Considerations concerning the winds of Adelie Land, Z. Gletscherkd. Glazialgeol., 10, 189-197.

Naithani, J., G. Mastrantonio, S. Argentini and P. PETTRÉ (2001): Influence of cyclonic perturbations on surface winds around Dumont d'Urville, East Antarctica using wavelet transform, J. Geophys. Res., 106 (D15), 17,093-17,102.

Naithani, J., H. GalléE and G. Schayes (2002): Marine air intrusion into the Adelie Land sector of East Antarctica - A study using regional climate model (MAR), J. Geophys. Res., 107 (D11), 10.1029/2000JD000274.

PARISH, T.R. (1988): Surface winds over the Antarctic continent: a review, Rev. Geophys., 26, 169-180.

PARISH, T.R. and D.W. BROMWICH (1998): A case study of Antarctic wind interaction with large-cale forcing, Mon. Weather Rev., 126, 199-209.

PARish, T.P, P. Pettré and G. Wendler (1993): The influence of large-scale forcing on the katabatic wind regime at Adelie Land, Antarctica, Meteorol. Atmos. Phys., 51, 165-176.

POOK, M. and L. COWLED (1999): On the detection of weather systems over Antarctic interior in the FROST analyses, Weather and Forecasting, 14, 920-929.

TAUBER, G.M. (1960): Characteristics of Antarctic katabatic winds, in Proceedings of the Symposium «Antarctic Meteorology», Melbourne, February 1959 (Pergamon Press, New York), 52-64. 